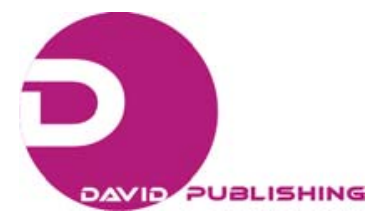

\title{
Drilling Titanium Aluminides with Twist Drills
}

\author{
Beranoagirre Aitor ${ }^{1}$, López de Lacalle L.N. ${ }^{2}$, Lamikiz A. ${ }^{2}$, Olvera D. ${ }^{2}$ and Urbicain G. ${ }^{2}$ \\ 1. University of the Basque Country, UPV-EUP, Plaza Europa $n^{\circ}$, San Sebastián 20018, Spain \\ 2. University of the Basque Country, UPV-ETSI, Alameda Urquijo s/n, Bilbao 48013, Spain
}

Received: July 30, 2010 / Accepted: September 09, 2010 / Published: February 10, 2011.

\begin{abstract}
Due to their high strength/weight ratio and resistance to corrosion and wear, superalloys such as gamma TiAl or Inconel 718 appear as the best choice at the sight of the demands in the vicinity of the combustion chamber. Such kind of parts suffer one last drilling operation at the end of the manufacturing process. The present work is framed within the study of twist drilling in advanced materials used for lightweight applications in aerospace sector. Within this context, the paper presents the results obtained from different tests in gamma TiAl alloys. Tool life tests were performed on three types of $\gamma$-TiAl (extruded MoCuSi, ingot MoCuSi and $\mathrm{TNB}$ ) to define an optimal set of cutting parameters.
\end{abstract}

Key words: Gamma TiAl, drilling, slight materials, superalloys.

\section{Introduction}

The interest of the air transport industry focused on the research of new materials that would open the way to support more demanding service conditions with the simultaneous target of lighter aircrafts.

Regarding to the aircraft engine, $\gamma$-TiAl intermetallic superalloys appear as a valid alternative in direct competition with nickel-based superalloys (Inconel, Waspalloy) where service temperatures exceed $800^{\circ} \mathrm{C}$. These alloys find their market in the high pressure area (compressor blades and stator) as well as in the low pressure zones (blades). The binomial TiAl provides a low density as well as high mechanical strength under high temperatures and corrosive environments [1]. These are complex alloys with high sensitivity to non-metallic impurities such as oxygen which need to be studied further.

The main difference between $\gamma$-TiAl alloy and other alloys such as Ti-6Al-4V lies on the aluminum levels $(43-48 \%$ in $\gamma$-TiAl and $6 \%$ in Ti-6Al-4V) which improves thermal conductivity in $\gamma$-TiAl, but

Corresponding author: Beranoagirre Aitor (1971- ), male, research fields: machine tool, machining. E-mail: Aitor.beranoagirre@ehu.es. worsening the ductile transition temperature which occurs between $600-800{ }^{\circ} \mathrm{C}$ depending on the microstructure and grain size.

In solid state, titanium alloys are found as alpha HCP (hexagonal close-packed structure) or beta BCC (body-centered cubic structure) phase. In pure state, the transition temperature between two phases is found at $882^{\circ} \mathrm{C}$, TiAl couple enabling solid solution hardening. Aluminum is the most common alloying element because of its ability to raise the beta transition temperature and its high solubility in both phases. Besides the alpha and beta phases, alpha 2 or $\mathrm{Ti}_{3} \mathrm{Al}$ and intermetallic gamma phase appear, both of capital significance in high temperature aerospace applications. The latter one is a face-centered cubic (FCC) L10 phase whose homogeneity ranges between $34 \%$ to $55 \%$ (\% in weight). Fig. 1 shows the relationship between microstructure and phase. The aluminum, oxygen, hydrogen and other alpha stabilizers increase the transition temperature between alpha/beta phase. On the other hand, beta-stabilizers (beta-eutectoid and beta-isomorphic) reduce the transformation temperature, causing a stable beta phase at room temperature. 


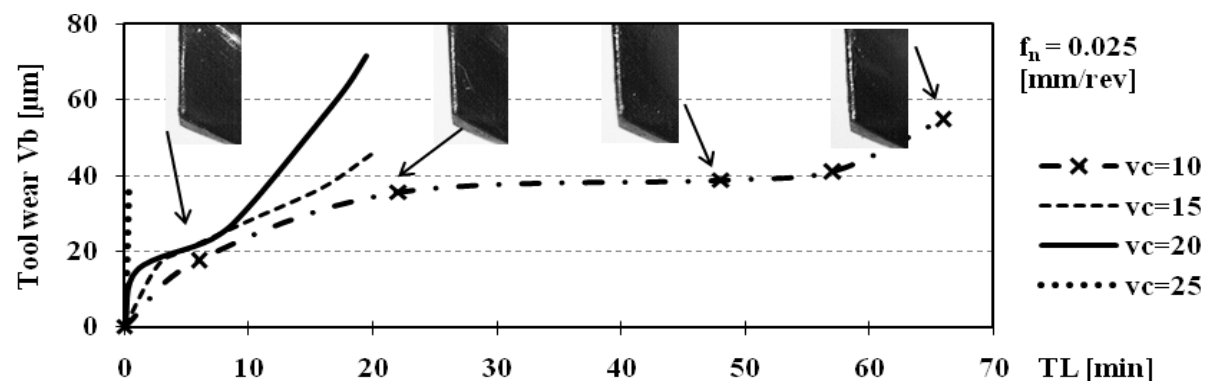

Fig. 1 Tool life in extruded MoCuSi (TL = Tool Life).

The following paper deals with the study of the behaviour of complex difficult-to-cut superalloys such as $\gamma$-TiAl [2]. Tool life tests have helped in defining a suitable set of parameters in drilling of three different types of $\gamma$-TiAl (extruded MoCuSi, ingot MoCuSi and TNB).

\section{Twist Drilling of $\gamma$-TiAl Superalloy}

The intermetallic gamma TiAl superalloys offer excellent mechanical properties [1], with low density $\left(4 \mathrm{gr} / \mathrm{cm}^{3}\right)$, high resistance at high temperatures, low electrical and thermal conductivity, oxidation resistance, ultimate strength of $1000 \mathrm{Mpa}$ and Young's modulus of $160 \mathrm{Gpa}$ [3]. There are three basic types of $\gamma$-TiAl superalloys: TNB [(44-45)Al - $(5-10) \mathrm{Nb}-$ (0.2-0.4)C], sustaining high levels of mechanical and oxidation resistance and used in aircraft applications at high temperatures $[4,5]$; MoCuSi type [(43-46)Al (1-2)Mo - (0.2)Si-Cu], for low temperatures applications and with high resistance below $650{ }^{\circ} \mathrm{C}$; finally, TNM [(43-45)Al - (5-8) Nb - Mo - (0-0.4)BC] for high temperature applications. There are two ways to manufacture these materials: solidified ingot or extruded alloy. In the first case, the alloy has the microstructure oriented in the direction of extrusion whereas in the case of melted and solidified alloys in the mould, the microstructure has no preferred orientation.

These materials are known by their low machinability and a study of the optimal cutting conditions [6] seems necessary. Table 1 shows the basic cutting data investigated during the experimental drilling tests. A set of optimal cutting parameters for a
Table 1 Tests procedure: $\mathrm{M} 1=$ extruded $\mathrm{MoCuSi}, \mathrm{M} 2=$ ingot $\mathrm{MoCuSi}$, M3 = TNB.

\begin{tabular}{llllll}
\hline $\mathrm{V}_{\mathrm{C}}$ & \multicolumn{5}{c}{$\mathrm{f}_{\mathrm{n}}(\mathrm{mm} / \mathrm{min})$} \\
\cline { 2 - 6 }$(\mathrm{m} / \mathrm{min})$ & 0.025 & 0.038 & 0.050 & 0.100 & 0.150 \\
\hline 10 & M1,M3 & M1,M3 & M1,M2,M3 & M1,M2,M3 & M2, M3 \\
15 & M1 & M1 & M1,M2,M3 & M1,M2,M3 \\
20 & M1 & M1 & M1,M2,M3 & \\
25 & M1 & & & & \\
\hline
\end{tabular}

reasonable tool life were obtained in extruded $\mathrm{MoCuSi}$, ingot MoCuSi and TNB [7].

Tests were carried out using carbide tools whose main geometrical characteristics are shown in Fig. 2. One of the critical aspects when drilling $\gamma$-TiAl is heat dissipation and chip evacuation due to the poor thermal conductivity.

Concerning this aspect, cutting tools are endowed with internal lubrication directly applied on the cutting edge, favouring chip evacuation. The cutting tools used were drills of $\varnothing 4$ and TF15 quality with Young's modulus of $580 \mathrm{GPa}$ and MIRACLE (Al, Ti)N coating type. The operations were performed for a depth of 20 $\mathrm{mm}(\mathrm{D} / \mathrm{L}=5)$ under a pressure of 8.5 bar for the refrigerant. The wear was observed with a microscope and the measurements were made on the digitized image of the tool. The well-known criterion $V_{B}=0.3$ of flank wear width, typical for turning/drilling operations, was employed: values above $0.3 \mathrm{~mm}$ were considered unacceptable. Figs. 1-3 show the wear curves under different cutting speeds for the three types of $\gamma$-TiAl alloys.

Table 2 shows that for the same cutting conditions, the tool has a longer life, 3 times higher when machining MoCuSi ingot than in TNB. In general, for 


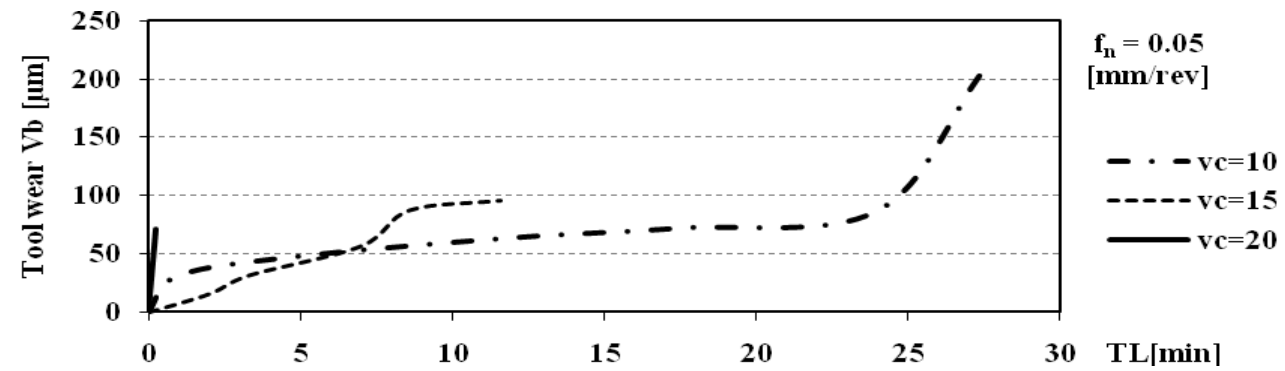

Fig. 2 Tool life in ingot MoCuSi (TL = Tool Life).

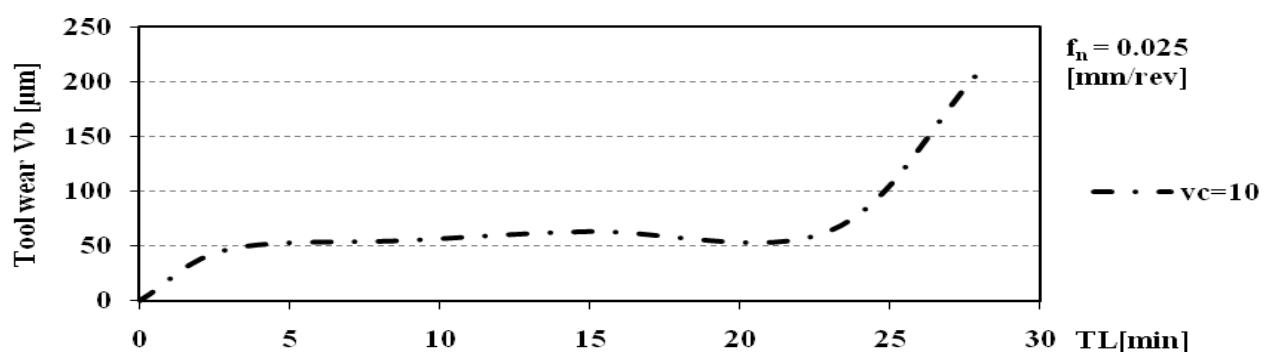

Fig. 3 Tool life in TNB (TL $=$ Tool Life).

Table 2 Tool life and wear vs materials/cutting conditions.

\begin{tabular}{|c|c|c|c|c|c|c|c|}
\hline \multirow[b]{2}{*}{$\mathrm{V}_{\mathrm{C}}(\mathrm{m} / \mathrm{min})$} & \multirow[b]{2}{*}{$\mathrm{f}_{\mathrm{n}}(\mathrm{mm} / \mathrm{rev})$} & \multicolumn{2}{|c|}{ Extruded $\mathrm{MoCuSi}$} & \multicolumn{2}{|c|}{ Ingot MoCuSi } & \multicolumn{2}{|c|}{ TNB } \\
\hline & & Time (min) & Wear $(\mu \mathrm{m})$ & Time (min) & Wear $(\mu \mathrm{m})$ & Time (min) & Wear $(\mu \mathrm{m})$ \\
\hline \multirow[t]{4}{*}{10} & 0.025 & 66 & 55 & - & - & 28 & 209.2 \\
\hline & 0.038 & 13.3 & 52.4 & - & - & 17.8 & 95.7 \\
\hline & 0.05 & 5.5 & 58.6 & 27.5 & 208 & 9.5 & 85 \\
\hline & 0.1 & 3 & 60 & 5 & 168.5 & 4.5 & 83.7 \\
\hline \multirow[t]{4}{*}{15} & 0.025 & 20 & 46 & - & - & - & - \\
\hline & 0.038 & 8.3 & 31.2 & - & - & - & - \\
\hline & 0.05 & 2.4 & 30 & 11.6 & 96 & 8 & 79.9 \\
\hline & 0.1 & & - & 2 & 93 & 0.5 & 55.4 \\
\hline \multirow[t]{4}{*}{20} & 0.025 & 19.5 & 71.5 & - & - & - & - \\
\hline & 0.038 & - & - & - & - & - & - \\
\hline & 0.05 & - & - & 0.25 & 71.5 & 2 & 63.5 \\
\hline & 0.1 & - & - & - & - & - & - \\
\hline \multirow[t]{4}{*}{25} & 0.025 & 0.4 & 39.3 & - & - & - & - \\
\hline & 0.038 & - & - & - & - & - & - \\
\hline & 0.05 & - & - & - & - & - & - \\
\hline & 0.1 & - & - & - & - & - & - \\
\hline
\end{tabular}

the three materials it can be stated that the optimal speed range is between $10-15 \mathrm{~m} / \mathrm{min}$ [8]. Higher speeds lead to accelerated wear of the tool, except in the case of extruded MoCuSi where machining times are about 20 min when $\mathrm{f}_{\mathrm{n}}=0.025 \mathrm{~mm} / \mathrm{rev}$.

Another aspect is the strong tendency of the drill to torsion failure which is very sensitive to an increase in cutting speed. This failure occurs catastrophically at approximately $45^{\circ}$ of the profile of the drill.

Based on the results from above, the following conditions are recommended for each of the materials:

Extruded MoCuSi: $\mathrm{V}_{\mathrm{C}}=10-15 \mathrm{~m} / \mathrm{min}, \mathrm{f}_{\mathrm{n}}=0.025$ $\mathrm{mm} / \mathrm{rev}$

MoCuSi ingot: $V_{C}=10-15 \mathrm{~m} / \mathrm{min}, \mathrm{f}_{\mathrm{n}}=0.050$. 
$\mathrm{mm} / \mathrm{rev}$

TNB: $V_{C}=10-15 \mathrm{~m} / \mathrm{min}, \mathrm{f}_{\mathrm{n}}=0.025 \mathrm{~mm} / \mathrm{rev}$ 。

\section{Conclusions}

During the present study was possible the evaluation of the hole making process on the difficult to cut $\gamma$-TiAl alloys with tungsten carbide coated tools using twist drilling. The results obtained offer feasible cutting parameters for the conventional drilling. From the results it is possible to conclude the ball helical milling process, previously studied for difficult to cut materials such as Inconel 718 as well as Ti6Al4V, showed a better advantage over the conventional drilling process in terms of tool life and process performance, avoiding the use of subsequent processes commonly used after drilling to remove the burrs.

The brittle behaviour of the TNB alloy was evident during simple hole making tests, even without a very high compressive stress process on an apparently strength plate $13.5 \mathrm{~mm}$ thick. Results make evident the current application scope of $\gamma$-TiAl alloys, and the inherent risk found during the machining of high added value and high liability workpieces.

\section{Acknowledgments}

Thanks are addressed to Mitsubishi Materials Corporation, for the cutting recommendations. Thanks are also addressed to Dinamill project funded by the Spanish Ministry of Education and Research, and to the 'CENIT Openaer' project.

\section{References}

[1] E.A. Loria, Vadis gamma titanium aluminide, Intermetallics 9 (2001) 997-1001.

[2] A.R.C. Sharman, D.K. Aspinwall, R.C. Dewesb, P. Bowen, Workpiece surface integrity considerations when finish turning gamma titanium aluminide, Wear 249 (2001) 473-481.

[3] D.K. Aspinwal, R.C. Dewes, A.L. Mantle, The machining of $\gamma$-TiAl intermetallic alloys, CIRP Annals -Manufacturing Technology 54 (2007) 99-104.

[4] T. Noda, Application of cast gamma TiAl for automobiles, Intermetallics 6 (1999) 709-713.

[5] M.A. Smit, J.M. Sykes, J.A. Hunter, J.D.B. Sharman, G.M. Scamans, Titanium based conversion coatings on aluminium alloy, Surface Engineering 1 (1999) 407-410.

[6] L.N. López de Lacalle, J.A. Sánchez, A. Lamikiz, High Performace Machining, Eds. Izaro, 2004.

[7] Y. Altintas, Manufacturing Automation: Metal Cutting Mechanics, Machine Tool Vibrations, and CNC Design, Cambridge University Press, ISBN 0-521-65029-1, Cambridge, United Kingdom, 2000.

[8] L.N. Lacalle, J. Pérez, J.L. Llorente, J.A. Sánchez, Advanced cutting conditions for the milling of aeronautical alloys, Journal of Materials Processing Technology 100 (2000) 1-11. 